\title{
Long non-coding RNA SENCR alleviates the inhibitory effects of rapamycin on human umbilical vein endothelial cells
}

\author{
HONGTAO SUN, SHUIYUN WANG and MIN SONG \\ Department of Cardiac Surgery, Cardiovascular Institute and Fu Wai Hospital, \\ Chinese Academy of Medical Sciences and Peking Union Medical College, Beijing 100037, P.R. China
}

Received November 12, 2017; Accepted May 4, 2018

DOI: $10.3892 / \mathrm{mmr} .2018 .9094$

\begin{abstract}
Rapamycin (RPM) is frequently used as the drug coating in drug-eluting stents (DESs) as it can inhibit the growth of smooth muscle cells. However, RPM also inhibits the proliferation and migration of vascular endothelial cells, and impairs reendothelialization in DES implantation. Therefore, the development of a strategy to protect vascular endothelial cells after DES implantation is of great importance. Long non-coding RNAs (lncRNAs) metastasis-associated lung adenocarcinoma transcript 1 (MALAT1) and smooth muscle and endothelial cell-enriched migration/differentiation-associated lncRNA (SENCR) are able to enhance the proliferation, migration and angiogenesis of endothelial cells, which suggests that they may have potential as antagonists of the adverse effects of RPM in DES. However, the relationship between RPM and lncRNAs in endothelial cells during the intervention is not fully understood at present. The current study investigated the role and potential mechanism of the IncRNA SENCR on the activity of human umbilical vein endothelial cells (HUVECs) after RPM treatment. The proliferation, migration, angiogenic capacity and cell cycle progression of lncRNA SENCR-overexpressing HUVECs following RPM treatment was examined. The proliferation-related proteins of IncRNA SENCR-modified HUVECs were evaluated to understand the mechanism of action. LncRNA SENCR significantly alleviated the inhibition of proliferation, migration, angiogenesis and cell cycle progression of HUVECs caused by RPM by activating extracellular signal-regulated kinase $1 / 2$ and mammalian target of RPM. The lncRNA SENCR could alleviate the inhibitory effects of RPM on HUVECs and may be useful as a new combinative agent to avoid the disadvantages of RPM in DES implantation.
\end{abstract}

Correspondence to: Dr Hongtao Sun, Department of Cardiac Surgery, Cardiovascular Institute and $\mathrm{Fu}$ Wai Hospital, Chinese Academy of Medical Sciences and Peking Union Medical College, 167 North Lishi Road, Beijing 100037, P.R. China

E-mail:drsunht@vip.163.com

Key words: rapamycin, lncRNAs, lncRNA SENCR, human umbilical vein endothelial cells, ERK1/2, mTOR

\section{Introduction}

Drug-eluting stents (DESs) have become the preferred choice to decrease stent thrombosis rates after stent implantation (1). Rapamycin (RPM), also known as sirolimus, is a macrolide compound that is usually used as an anti-proliferative and immunosuppressive drug to prevent rejection of transplanted organs. Along with the well-known CYPHER ${ }^{\mathrm{TM}}$ sirolimus-eluting stents, RPM-eluting stents have been widely used to inhibit vascular smooth muscle cell proliferation and therefore decrease the restenosis rates of the implanted stents $(2,3)$. Although RPM has a remarkable anti-thrombotic action when eluted from the stent, it also inhibits endothelial cell proliferation, which impairs re-endothelialization after DES implantation $(4,5)$. Therefore, the attenuation of RPM-induced injury of vascular endothelial cells is of great importance to the development of new RPM-eluting stents.

Long non-coding RNAs (lncRNAs) have emerged as novel regulators of gene expression and are able to regulate several cellular processes, such as proliferation, migration, invasion and chemoresistance (6-13). Additionally, lncRNAs are also involved in cardiovascular development and pathophysiology (14). Michalik et al (15), provided the first evidence for the regulation of vascular endothelial cell functions, such as migration and sprouting, by lncRNA metastasis-associated lung adenocarcinoma transcript 1 (MALAT1). Besides, smooth muscle and endothelial cell-enriched migration/differentiation-associated lncRNA (lncRNA SENCR), also known as FLI1-AS1 or IncRNA9, has been confirmed to have the capacity to stabilize the differentiated state and maintain contractile phenotype of smooth muscle cells (16). LncRNA SENCR, highly expressed in endothelial cells, smooth muscle cells and aortic tissue and a recent study demonstrated that a high level of lncRNA SENCR promoted the sprouting of cultured endothelial cells, as well as the expression of proangiogenic genes, suggesting enhancement of endothelial cell function (17). However, the mechanisms of vascular endothelial cell functions regulation by lncRNAs especially under RPM existing remain largely unknown.

Based on these findings, we speculated that there may be an association between RPM and lncRNAs in the inhibition of proliferation and migration of vascular endothelial cells. To validate this hypothesis, in the present study, we selected two relevant lncRNAs MALAT1 and SENCR, especially lncRNA 
SENCR, and chose the stable endothelial cell line HUVEC to investigate the underlying mechanisms post RPM treatment. The results suggested the potential application of lncRNA SENCR as endothelial cell function predictors and provided a promising candidate for intervention of the side effect of RPM in patients who received RPM-eluting stents.

\section{Materials and methods}

Cell culture and RPM treatment. Human umbilical vein endothelial cells (HUVECs; ATCC ${ }^{\circledR}$ PCS-100-013) were bought from ACTT (Manassas, VA, USA) and were cultured in RPMI 1640 medium (HyClone; GE Healthcare Life Sciences, Logan, UT, USA) supplemented with $10 \%$ fetal bovine serum (Gibco; Thermo Fisher Scientific, Inc., Waltham, MA, USA), 100 U/ml penicillin and $100 \mu \mathrm{g} / \mathrm{ml}$ streptomycin at $37^{\circ} \mathrm{C}$ in $5 \% \mathrm{CO}_{2}$. HUVECs in the logarithmic growth phase were digested with trypsin and then cell suspensions of $1-5 \times 10^{4}$ cells $/ \mathrm{ml}$ were made. A total of $100 \mu \mathrm{l}$ of the above cell suspensions was seeded per well in 96-well plates in triplicate. RPM (Selleck Chemicals, Houston, TX, USA) solutions at serials of concentrations ( 0,1 , 10 and $100 \mathrm{nM}$ ) were added to the cells. After incubation for another 48 h, a Cell Counting Kit-8 (CCK8) assay was used to determine the appropriate RPM concentration for subsequent experiments.

The appropriate intervention time for RPM treatment was then determined. HUVECs were treated with the selected RPM concentration determined by the above CCK8 experiment and were cultured for $0,24,48$ and $72 \mathrm{~h}$. The control group treated with an equal volume of pbs instead at each time point was normally cultured and treated with no RPM. The CCK8 assay was then performed.

CCK8 assay. A CCK8 assay was performed according to the supplier's instructions (Beyotime Institute of Biotechnology, Haimen, China). Specifically, $10 \mu \mathrm{lCCK}-8$ and $90 \mu 1$ serum-free culture medium were added to each well and cultured at $37^{\circ} \mathrm{C}$ and $5 \% \mathrm{CO}_{2}$ for $1 \mathrm{~h}$. The absorbance at $450 \mathrm{~nm}$ wavelength was measured with a plate reader (DNM-9602, Beijing, China) and the value of each well was recorded.

Expression of endogenous lncRNAs MALAT1 and SENCR. The mRNA from each group of cells was extracted and reverse transcribed into cDNA using reverse transcription kit (Fermentas; Thermo Fisher Scientific, Inc.). The resultant cDNA was used as a template for quantitative polymerase chain reaction (qPCR) detection. The primers for lncRNAs MALAT1 and SENCR are listed in Table I. $\beta$-actin was used as the reference gene. qPCR procedure followed the standard procedure of the SYBR-Green PCR kit (Thermo Fisher Scientific, Inc.): $95^{\circ} \mathrm{C}$ for $10 \mathrm{~min}$, followed by 40 cycles of $95^{\circ} \mathrm{C}$ for $15 \mathrm{sec}$ and $60^{\circ} \mathrm{C}$ for $45 \mathrm{sec}$, then $95^{\circ} \mathrm{C}$ for $15 \mathrm{sec}, 60^{\circ} \mathrm{C}$ for $1 \mathrm{~min}, 95^{\circ} \mathrm{C}$ for $15 \mathrm{sec}$ and $60^{\circ} \mathrm{C}$ for $15 \mathrm{sec}$. The results were analyzed with real-quantitative PCR \& the $2^{-\Delta \Delta \mathrm{Ct}}$ method.

Construction and transfection of the IncRNA SENCR overexpression plasmid. The plasmid pcDNA 3.1+ $(1.52 \mu \mathrm{g} / \mu \mathrm{l}$; Invitrogen; Thermo Fisher Scientific, Inc.) was used to construct the overexpression vector for IncRNA SENCR. Specifically, EcoR1 and Not1 restriction enzyme sites were introduced to clone SENCR which was synthesized in vitro and this created a EcoR1-SENCR-Not1 fragment, then the full-length SENCR sequence was ligated to pcDNA 3.1+ vector with DNA ligase. Finally, the recombinant plasmid was verified by sequencing analysis. The transfection was performed according to the recommended protocol of Lipofectamine ${ }^{\mathrm{TM}} 2000$ (Invitrogen; Thermo Fisher Scientific, Inc.) as follows: i) HUVEC cells in the logarithmic growth phase were cultured at $5 \times 10^{5}$ cells per well in a 6 -well culture plate and incubated at $37^{\circ} \mathrm{C}$ and $5 \% \mathrm{CO}_{2}$ for $24 \mathrm{~h}$; ii) the culture medium was changed to serum-free opti-MEM medium (Gibco; Thermo Fisher Scientific, Inc.) $2 \mathrm{~h}$ before transfection; iii) the transfection reagent Lipofectamine ${ }^{\mathrm{TM}} 2000$ was diluted in opti-MEM at 1:20, and the mixture was kept at room temperature for $5 \mathrm{~min}$; iv) Lipofectamine 2000 and lncRNA SENCR-overexpression plasmid $(2.5 \mu \mathrm{g} /$ well, empty plasmid vector with equivalent concentration was used as control in the transfection experiment) were mixed gently and kept at room temperature for $20 \mathrm{~min}$; v) the mixture was added to the wells with $200 \mu \mathrm{l}$ per well and the plate was cultured in the incubator at $37^{\circ} \mathrm{C}$ and $5 \%$ $\mathrm{CO}_{2}$ for $6 \mathrm{~h}$; vi) the mixture was aspirated and replaced with a complete medium and vii) the plate was cultured overnight at $37^{\circ} \mathrm{C}$ and $5 \% \mathrm{CO}_{2}$.

Proliferation, migration and angiogenesis of HUVECs. In all the proliferation, migration and angiogenesis experiments, cells were firstly treated by control medium, lncRNA SENCR overexpression (lncRNA SENCR OE), RPM (100 nM) or RPM plus lncRNA SENCR OE (RPM+lncRNA SENCR OE) for $24 \mathrm{~h}$. For the detection of proliferation, CCK8 assay was used and the procedure was the same as described above. For the analysis of cell migration, scratch test and transwell test were performed. The wound was measured at 0,8 and $12 \mathrm{~h}$ in the scratch test. In the transwell test, the above treated cells were collected and reseeded into the up chamber of the transwell insert (24-well plate; Corning Incorporated, Corning, NY, USA) at the density of $2 \times 10^{5}$ cells per well with $200 \mu \mathrm{l}$ serum free basic medium. $500 \mu \mathrm{l}$ complete endothelial cell growth medium was placed in the lower chamber. The cells were incubated for $12 \mathrm{~h}$ at $37^{\circ} \mathrm{C}$. Cells migrated to the lower surface of the filter were fixed with $70 \%$ methanol and stained with $0.5 \%$ crystal violet solution and then were imaged (magnification, $\mathrm{x} 100$ ). For the quantification of the migrated cells, cell numbers were counted in 4 randomly selected fields (magnification, x100). For angiogenesis detection, Matrigel was dissolved overnight at $4^{\circ} \mathrm{C}$ before being used. A total of $50 \mu \mathrm{l}$ per well was added and incubated at $37^{\circ} \mathrm{C}$ for $1 \mathrm{~h}$. The above treated cells were collected and reseeded into the Matrigel-coated wells at a density of $10^{4}$ cells per well. After 4 and $8 \mathrm{~h}$ of incubation at $37^{\circ} \mathrm{C}, 4$ fields of view (magnification, $\mathrm{x} 200$ ) were selected per well to analyze the tube length and the number of branches of the blood vessels.

Cell cycle analysis of HUVECs. After $24 \mathrm{~h}$ treatment with RPM, the cell cycle stage was detected in the HUVECs by flow cytometry. The cells were collected and stained by PI (Sigma-Aldrich; Merck KGaA, Darmstadt, Germany) staining. Specifically: i) the cells were washed by PBS twice and the cell concentration was set at $1 \times 10^{6} / \mathrm{ml}$; ii) the cell suspension was fixed at $70 \%$ ethanol at $-20^{\circ} \mathrm{C}$ for $24 \mathrm{~h}$ and washed with 
Table I. Primer sequences.

Gene

MALAT1

SENCR

$\beta$-actin
Forward primer (5'-3')

Reverse primer $\left(5^{\prime}-3^{\prime}\right)$

MALAT1, metastasis-associated lung adenocarcinoma transcript 1; SENCR, smooth muscle and endothelial cell-enriched migration/differentiation-associated RNA.

PBS before staining; iii) $100 \mu \mathrm{g} / \mathrm{ml}$ RNase A was added and the mixture was incubated at $37^{\circ} \mathrm{C}$ for $30 \mathrm{~min}$; iv) $50 \mu \mathrm{g} / \mathrm{ml} \mathrm{PI}$ solution was added and the mixture was incubated at $4^{\circ} \mathrm{C}$ for 30 min in the dark; v) the sample was run on machine and the recording excitation wavelength was $488 \mathrm{~nm}$ and vi) cell cycle analysis was performed with FLOWJO software (v7.6.2).

mRNA expression of vascular endothelial growth factor (VEGFA), vascular cell adhesion protein-1 (VCAM-1) and p21. Total mRNA was extracted and then reverse transcribed into cDNA. The resultant cDNA was used as the template for qPCR detection. The qPCR primers for VEGFA, VCAM-1 and $p 21$ are listed in Table II. $\beta$-actin was used as the reference gene. The qPCR procedure followed the standard thermocycling protocol: $95^{\circ} \mathrm{C}$ for $10 \mathrm{~min}$, followed by 40 cycles of $95^{\circ} \mathrm{C}$ for $15 \mathrm{sec}$ and $60^{\circ} \mathrm{C}$ for $45 \mathrm{sec}$, then $95^{\circ} \mathrm{C}$ for $15 \mathrm{sec} ; 60^{\circ} \mathrm{C}$ for $1 \mathrm{~min}$, $95^{\circ} \mathrm{C}$ for $15 \mathrm{sec}$ and $60^{\circ} \mathrm{C}$ for $15 \mathrm{sec}$. The results were analyzed with the real-quantitative PCR \& the $2^{-\triangle \Delta C q}$ method (18).

Protein expression of the RPM-related signaling pathway in HUVECs. HUVECs were cultured in 6-well plates for $24 \mathrm{~h}$, then the total protein was extracted. Western blotting was performed to detect the protein expression levels of phosphorylated (p-ERK1/2, ERK1/2, p-mTOR and mTOR, with GAPDH as the reference gene. The procedure of western blotting followed the standard protocol. In brief, about $10^{6}$ cells were taken and lysed and the total protein was obtained; a $10 \%$ SDS-PAGE gel was prepared; $30 \mu \mathrm{g}$ total protein was loaded in each lane and gel electrophoresis was performed at $60 \mathrm{~V}$ for $30 \mathrm{~min}$ and then at $90 \mathrm{~V}$ for $1 \mathrm{~h}$; the protein bands on the gel were transferred to a polyvinylidene difluoride (PVDF) membrane under a steady current of $200 \mathrm{~mA}$ for $120 \mathrm{~min}$; the PVDF membrane was blocked with $5 \%$ skimmed milk powder for $2 \mathrm{~h}$, then the membrane was incubated with appropriate antibodies for p-ERK1/2 (Affinity, AF1014), ERK1/2 (Affinity, AF0155), p-mTOR (Affinity, AF3308), mTOR (Affinity, AF6308) with a dilution ratio of 1:1,000 and GAPDH (ab37168; Abcam) as the reference with a dilution ratio of 1:2,000. For chemiluminescence detection, an ECL western blotting kit (Thermo Fisher Scientific, Inc.) was used to react with the interest proteins. Tanon Automatic Chemiluminescence Image Analysis System (5200, China) was used to scan the light bands 5 min after the reaction and the matching software accompanying the machine was used for analysis.

Statistical analysis. Data were analyzed with SPSS v19 statistical software (SPSS, Inc., Chicago, IL, USA). All
Table II. Quantitative polymerase chain reaction primer sequences.

\begin{tabular}{ll}
\hline Primer & \multicolumn{1}{c}{ Sequence (5'-3') } \\
\hline hVEGFA_F & TCACCAAGGCCAGCACATAG \\
hVEGFA_R & TCGTTTTTGCCCCTTTCCCT \\
hP21_F & TCCTCATCCCGTGTTCTCCT \\
hP21_R & ACAAGTGGGGAGGAGGAAGT \\
hVCAM1_F & AGATTGGTGACTCCGTCTCA \\
hVCAM1_R & TCATTGTCAGCGTAGATGTGG \\
h $\beta$-actin_F & CATCGTCCACCGCAAATGCTTC \\
h $\beta$-actin_R & AACCGACTGCTGTCACCTTCAC
\end{tabular}

VEGF, vascular endothelial growth factor; VCAM-1, vascular cell adhesion protein-1; F, forward; $\mathrm{R}$, reverse; $\mathrm{h}$, human.

data are presented in the form of mean \pm standard deviation. Comparisons among $>2$ groups were performed with one-way analysis of variance followed by the least significant difference post hoc method, and comparisons between two groups were performed with Student's t-test. $\mathrm{P}<0.05$ was considered to indicate a statistically significant difference.

\section{Results}

Effect of RPM treatment on the proliferation of HUVECs. To confirm the effect of RPM on the proliferation of vascular endothelial cells, a CCK8 assay was performed on the HUVECs. As shown in Fig. 1, compared with the control group (0 nM RPM treatment), the proliferative capacity of HUVECs was significantly inhibited in a concentration-dependent manner. Specifically, the rate of inhibition was about $50 \%$ when the $\mathrm{RPM}$ concentration was $100 \mathrm{nM}$. Since the suppression was the most effective at this concentration, we selected $100 \mathrm{nM}$ RPM to be taken forward in the present study. An obviously inhibited HUVECs proliferation after RPM treatment (100 nM) at all the time points could be observed (Fig. 1B). Therefore, to study the relationship between IncRNA SENCR and RPM treatment on HUVEC behavior, treatment with $100 \mathrm{nM}$ RPM for $24 \mathrm{~h}$ was used in the follow-up experiments.

RPM treatment downregulates the endogenous expression of IncRNAs MALAT1 and SENCR in HUVECs. To study the relationship between RPM treatment and the endogenous 

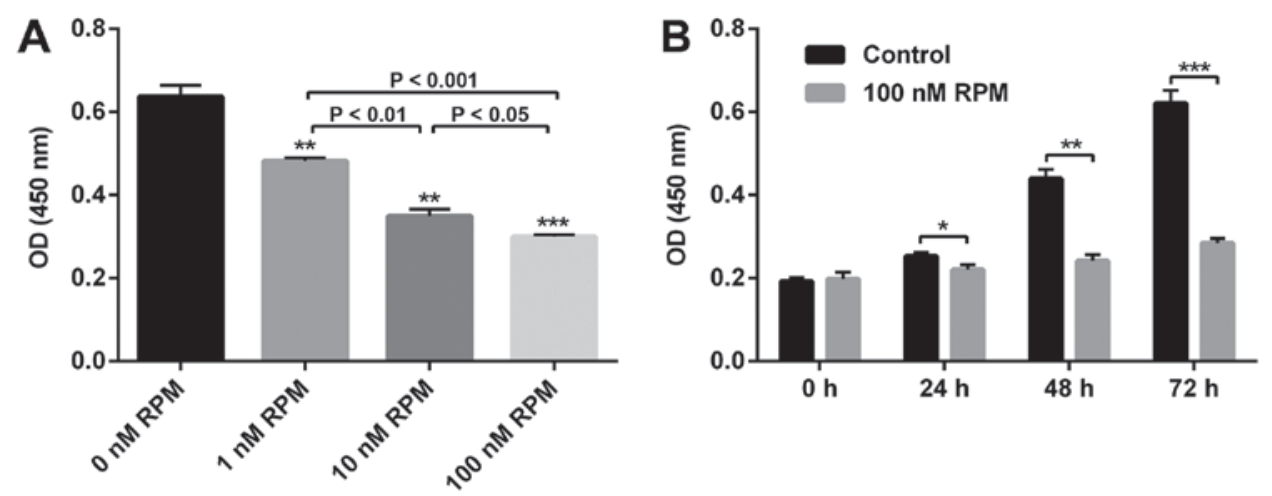

Figure 1. (A) Effect of RPM on the cell proliferation of HUVECs at different concentrations for 48 h. ${ }^{* * *} \mathrm{P}<0.01 \mathrm{vs} .0 \mathrm{nM}$ RPM, ${ }^{* * *} \mathrm{P}<0.001 \mathrm{vs} .0 \mathrm{nM}$ RPM. (B) Proliferation of HUVECs after $100 \mathrm{nM}$ RPM treatment at different time points. ${ }^{*} \mathrm{P}<0.05,{ }^{* * *} \mathrm{P}<0.01,{ }^{* * * *} \mathrm{P}<0.001$. RPM, rapamycin; HUVEC, human umbilical vein endothelial cell; OD, optical density.
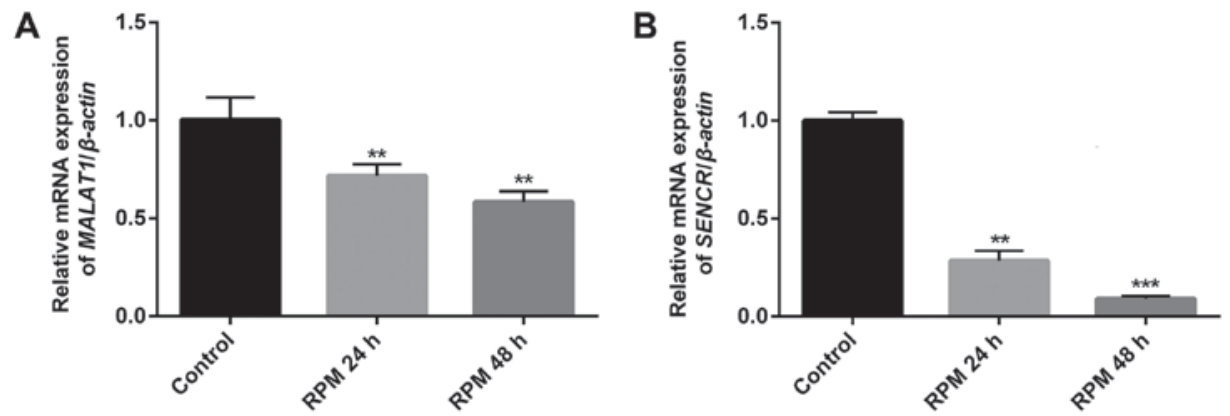

Figure 2. Effect of $100 \mathrm{nM}$ RPM treatment on the expression of two lncRNAs MALAT1 and SENCR at different time points. (A) MALAT1; (B) SENCR. ${ }^{* *} \mathrm{P}<0.01,{ }^{* * *} \mathrm{P}<0.001$ vs. the control group. RPM, rapamycin; SENCR, smooth muscle and endothelial cell-enriched migration/differentiation-associated long noncoding RNA; lnc, long non-coding; MALAT1, metastasis associated lung adenocarcinoma transcript 1.

expression of the two vascular endothelial cell function-related IncRNAs, MALAT1 and SENCR, in HUVECs, qPCR analysis was performed. Fig. 2 showed that both lncRNAs MALAT1 $(\mathrm{P}<0.01)$ and SENCR $(\mathrm{P}<0.01$ in $24 \mathrm{~h}$ and $\mathrm{P}<0.001$ in $48 \mathrm{~h})$ genes were significantly downregulated in HUVECs after exposure to $100 \mathrm{nM}$ RPM. It was noted that IncRNA SENCR showed a more remarkable downregulation than IncRNA MALAT1 after RPM treatment in $48 \mathrm{~h}$. Therefore, IncRNA SENCR was selected to study the effect of IncRNA on the cellular functions of vascular endothelial cells after RPM treatment.

Validation of the overexpression of IncRNA SENCR. After the construction and transfection of the lncRNA SENCR-overexpression plasmid, we verified the overexpression of lncRNA SENCR in HUVECs. As shown in Fig. 3A, compared with the control group, the relative expression of the SENCR gene in transfected HUVECs was significantly increased, indicating the successful overexpression of lncRNA SENCR in HUVECs $(\mathrm{P}<0.001)$.

To study the effects of RPM treatment and overexpression of lncRNA SENCR on the functions of vascular endothelial cells, proliferation, migration and angiogenesis analysis of HUVECs was performed in detail. Firstly, the proliferation of HUVECs in Fig. 3B showed that compared with the control group, the lncRNA SENCR overexpression group enhanced and RPM treatment (100 $\mathrm{nM}$ for $24 \mathrm{~h}$ ) decreased proliferation of HUVECs. However, RPM treatment associated with SENCR overexpression (RPM+lncRNA-SENCR OE) showed increased proliferation compared with RPM treatment alone. These results indicate that RPM could inhibit the proliferation of HUVEC cells and overexpression of IncRNA SENCR could alleviate the inhibitory effect of RPM on the proliferation of HUVECs.

Effects of RPM treatment and overexpression of IncRNA SENCR on the functions of HUVECs. We then examined the migration profile of HUVECs. The results of the scratch assay showed that IncRNA SENCR overexpression obviously decreased the scratch width of HUVECs, at either 8 or $12 \mathrm{~h}(\mathrm{P}<0.001$ vs. control; Fig. 4A and B) and RPM treatment significantly inhibited the cell migration, which got effectively relieved by high level of lncRNA SENCR $(\mathrm{P}<0.01$ vs. RPM at $8 \mathrm{~h}, \mathrm{P}<0.05$ vs. RPM at $12 \mathrm{~h}$; Fig. $4 \mathrm{~A}$ and B). However, interestingly, the RPM+lncRNA-SENCR OE group demonstrated a smaller scratch width than the RPM group. Transwell assay provided a similar data (Fig. 4C and D) and it revealed that lncRNA SENCR upregulation partly reversed the inhibitory effect on cell migration in presence of RPM. These results suggest that RPM inhibits the migration of HUVECs and overexpression of the lncRNA SENCR could alleviate the inhibitory effect of RPM on the migration of HUVECs.

The angiogenesis detection was performed using the Matrigel method. The results in Fig. 5 are after cultivation for 4 and $8 \mathrm{~h}$. Compared with the control group, the number and length of branches were significantly increased in the lncRNA-SENCR OE group and significantly reduced in 

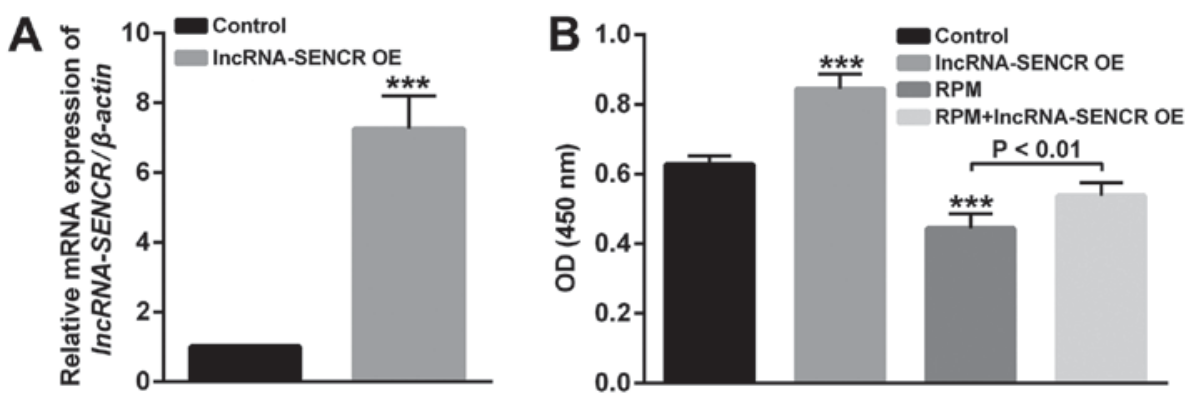

Figure 3. (A) Relative expression levels of lncRNA SENCR in HUVECs. (B) The proliferation profile of HUVECs detected by Cell Counting Kit-8 assay after RPM (100 nM for $24 \mathrm{~h}$ ) and lncRNA SENCR overexpression treatment. ${ }^{* * * *} \mathrm{P}<0.001$ vs. Control. Control: Cells were transfected with empty vector. lnc, long non-coding; SENCR, smooth muscle and endothelial cell-enriched migration/differentiation-associated RNA; HUVEC, human umbilical vein endothelial cell; RPM, rapamycin; OE, overexpression; OD, optical density.
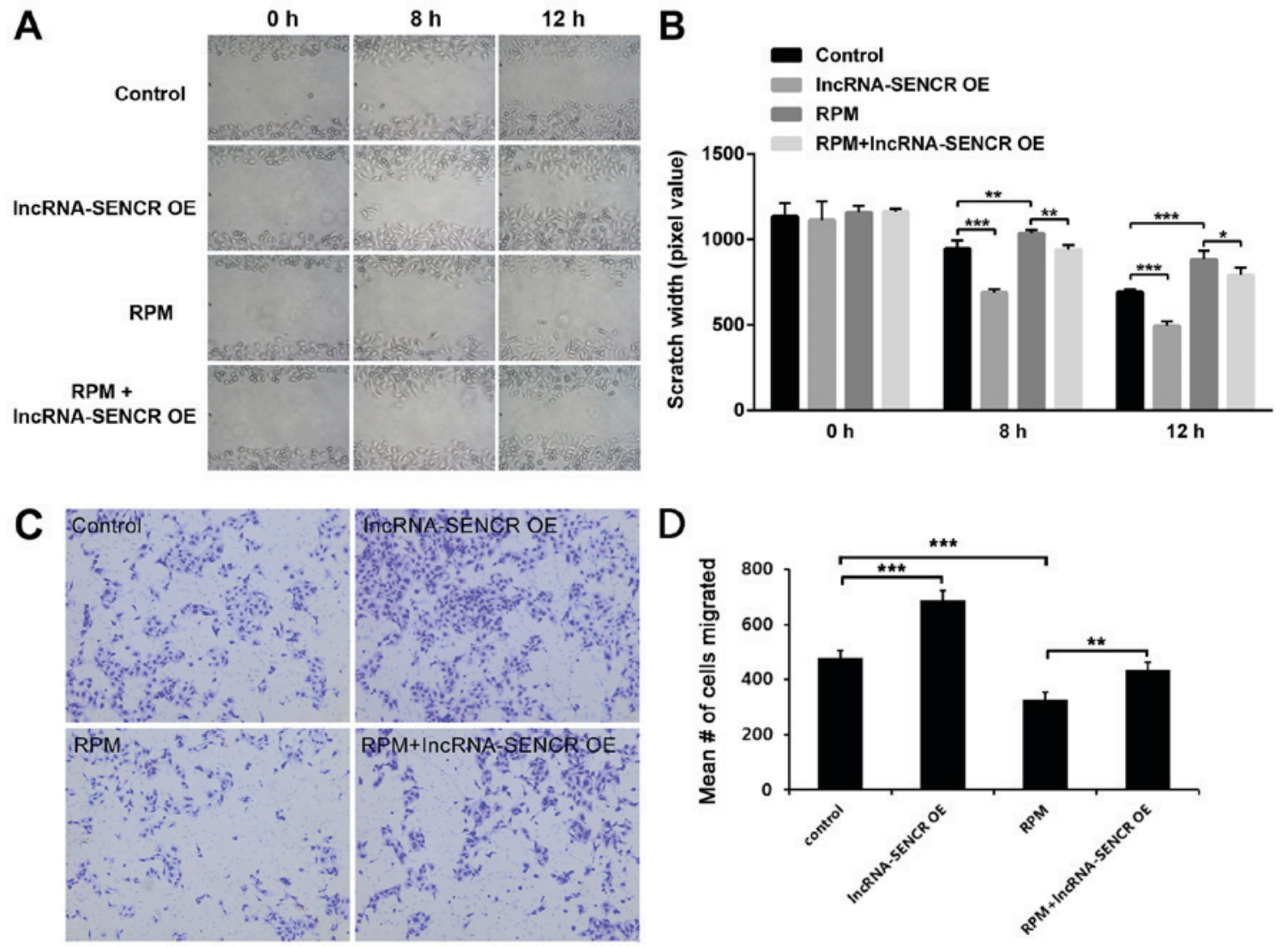

Figure 4. Migration assay of HUVECs after treatments with lncRNA-SENCR OE, RPM and RPM+lncRNA-SENCR OE. (A) Representative images of the scratch growth assay for all groups at 8 and $12 \mathrm{~h}$. (B) Quantitative analysis of the scratch growth assay $(\mathrm{n}=3)$. (C) Representative images of the transwell assay for all groups at $12 \mathrm{~h}$. (D) Quantification of migrated cells in the transwell assay. Magnification in (A) and (C) was x100. ${ }^{*} \mathrm{P}<0.05,{ }^{* *} \mathrm{P}<0.01,{ }^{* * * *} \mathrm{P}<0.001$. HUVEC, human umbilical vein endothelial cell; lnc, long non-coding; SENCR, smooth muscle and endothelial cell-enriched migration/differentiation-associated RNA; RPM, rapamycin; OE, overexpression.

the RPM treatment group at $8 \mathrm{~h}(\mathrm{P}<0.01)$. However, consistent with the aforementioned cellular function results, the RPM+lncRNA-SENCR OE group showed an increased cell branch number and increased vessel length compared with the RPM treatment group alone, indicating that the overexpression of lncRNA SENCR relieves the inhibitory effect of RPM treatment on angiogenesis in HUVECs.

Effects of RPM treatment and overexpression of lncRNA SENCR on the cell cycle of HUVECs. The effect of RPM treatment and overexpression of IncRNA SENCR on cell cycle progression was detected by flow cytometry. The flow cytometry analysis in Fig. 6 showed that the IncRNA-SENCR OE group had a reduced proportion of G0/G1 phase cells and the RPM treatment group had an increased proportion of G0/G1 phase cells compared with the control group. Not unexpectedly and also consistent with the above results, there was a decreased proportion of G0/G1 phase cells in the RPM+lncRNA-SENCR OE group. These data demonstrate that RPM treatment (100 nM for $24 \mathrm{~h})$ blocks the proliferation of HUVECs in the G0/G1 stage, and overexpression of lncRNA SENCR could reverse the blocking effect of RPM on 
A
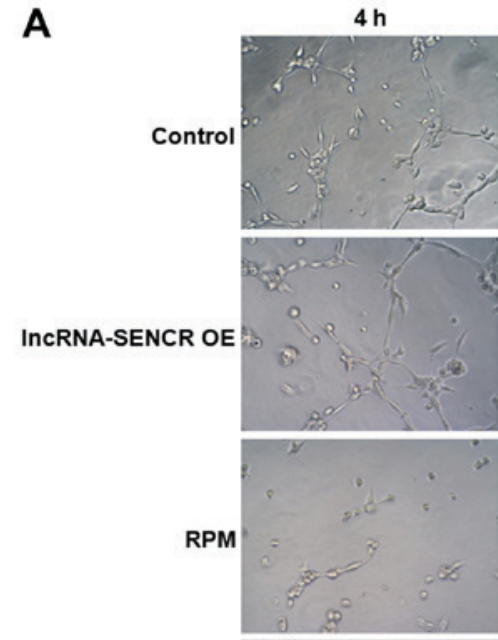

RPM+ InCRNA-SENCR OE
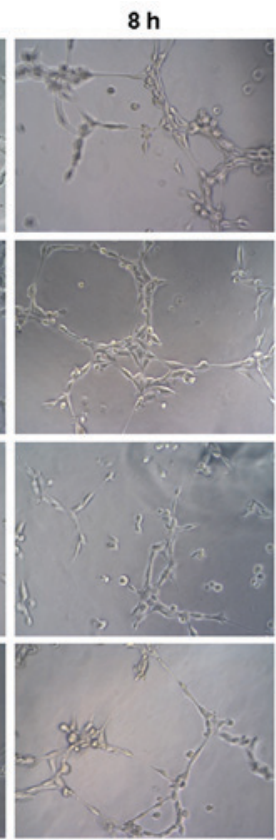
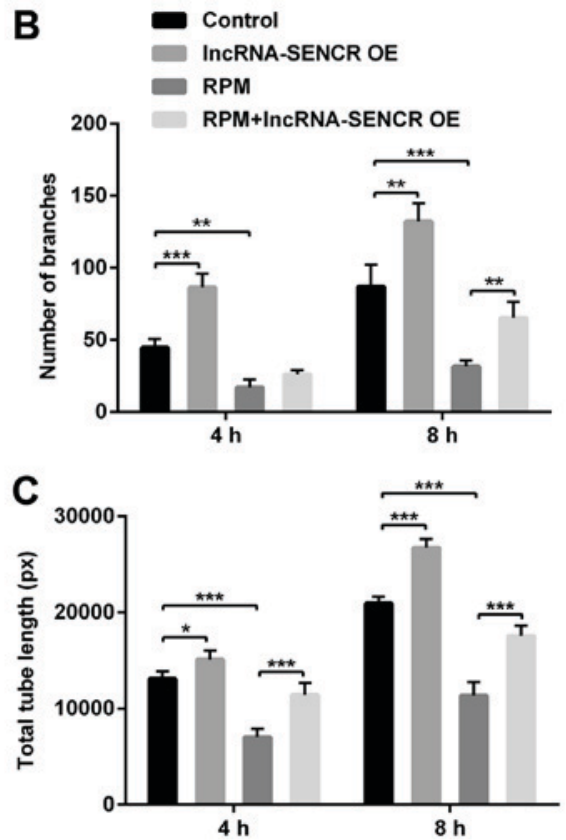

Figure 5. Angiogenic ability of HUVECs after treatment with lncRNA-SENCR OE, RPM and RPM+lncRNA-SENCR OE. (A) Representative images of angiogenesis. (B) Quantitative analysis of the branch growth $(\mathrm{n}=3)$. (C) Quantitative analysis of the tube length ( $\mathrm{n}=3$ ). Magnification in (A) was $x 100$. "P<0.05, ${ }^{* *} \mathrm{P}<0.01,{ }^{* * *} \mathrm{P}<0.001$. HUVEC, human umbilical vein endothelial cell; lnc, long non-coding; SENCR, smooth muscle and endothelial cell-enriched migration/differentiation-associated RNA; OE, overexpression; RPM, rapamycin; ns, non-significant.

A
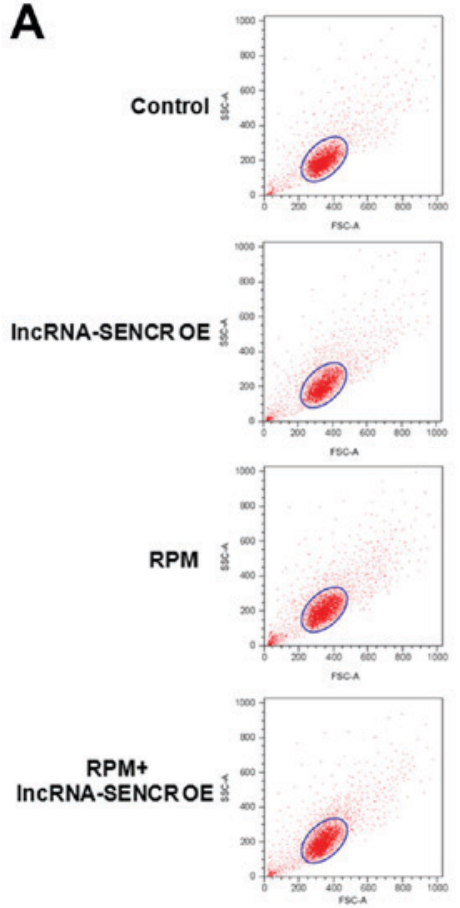
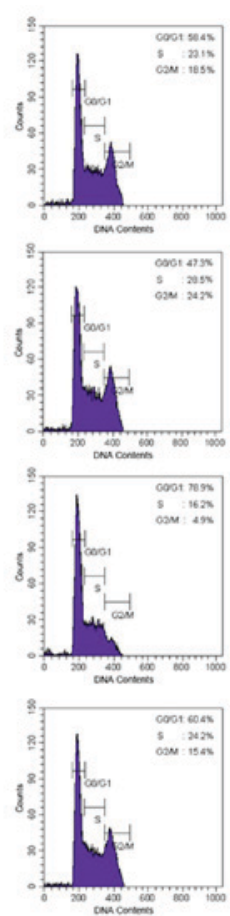

B
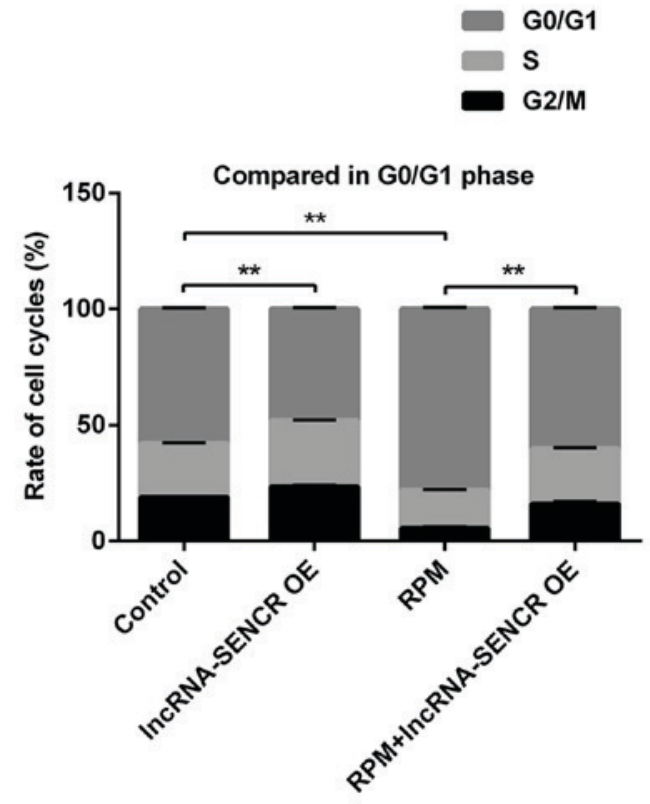

Figure 6. Cell cycle analyses of HUVECs after treatments with lncRNA-SENCR OE, RPM and RPM+lncRNA-SENCR-OE. (A) Representative images of flow cytometry analysis. (B) Quantitative analysis of the distribution of cells between different cell cycle stages $(\mathrm{n}=3){ }^{*}{ }^{* *} \mathrm{P}<0.01$. HUVEC, human umbilical vein endothelial cell; lnc, long non-coding; SENCR, smooth muscle and endothelial cell-enriched migration/differentiation-associated RNA; OE, overexpression; RPM, rapamycin.

HUVEC proliferation and decreased the percentage of G0/G1 cells from 78.9 to $60.4 \%$.

Effects of RPM treatment and overexpression of IncRNA SENCR on the expression of VEGFA, p21 and VCAM-1. In order to further investigate the mechanism that supports the above results, we performed analysis by qPCR of the level of related genes in HUVECs after different treatments. Fig. 7 showed that the VEGFA and VCAM-1 genes were significantly downregulated after RPM treatment, however 

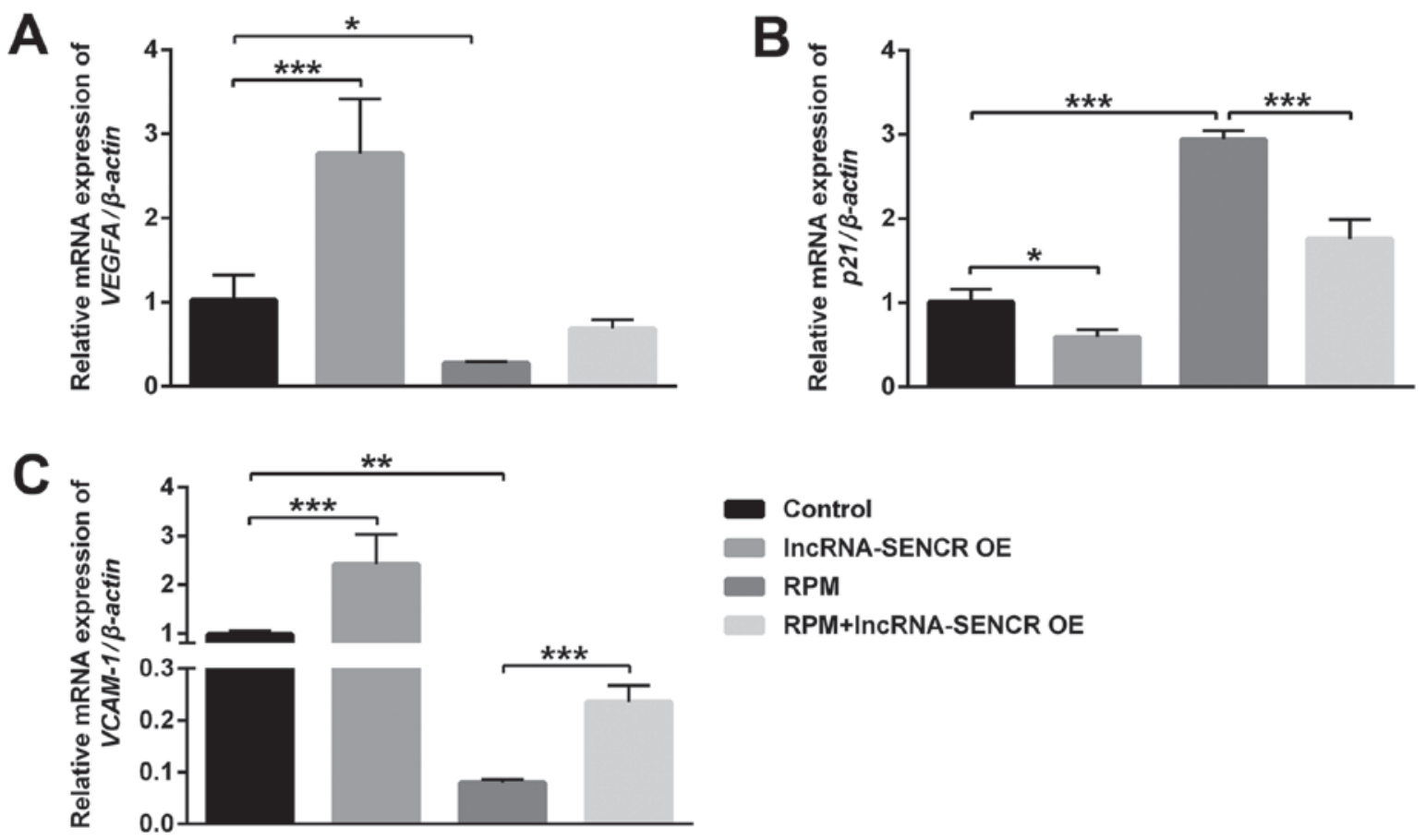

Figure 7. mRNA expression of VEGFA, $p 21$ and $V C A M-1$ of HUVECs after treatments with lncRNA-SENCR OE, RPM and RPM+lncRNA-SENCR OE (A) VEGFA. (B) p21. (C) VCAM-1. (n=3). " $\mathrm{P}<0.05,{ }^{* *} \mathrm{P}<0.01,{ }^{* * * *} \mathrm{P}<0.001$. VEGF, vascular endothelial growth factor; VCAM-1, vascular cell adhesion protein-1; HUVEC, human umbilical vein endothelial cell; lnc, long non-coding; SENCR, smooth muscle and endothelial cell-enriched migration/differentiation-associated RNA; OE, overexpression; RPM, rapamycin.

the $p 21$ gene was remarkably upregulated $(\mathrm{P}<0.01)$. Moreover, RPM+lncRNA-SENCR OE treatment reversed the expression of VEGFA almost to control cells $(\mathrm{P}=0.053$; Fig. $7 \mathrm{~A})$ and significantly relieved the upregulation of the $p 21$ gene and downregulation of the VCAM-1 gene caused by RPM treatment $(\mathrm{P}<0.05$; Fig. $7 \mathrm{~B}$ and $\mathrm{C})$.

p21 is a negative regulator of the cell cycle, which can arrest the cell cycle in the G1 phase and inhibit DNA replication. VEGFA and VCAM-1 are related genes for vascular endothelial growth and cell adhesion. These results demonstrate that RPM treatment could inhibit angiogenesis and cell proliferation, and the overexpression of the lncRNA SENCR could alleviate the inhibitory effect of RPM on the angiogenesis and proliferation of HUVECs.

Effects of RPM and IncRNA SENCR on p-ERK1/2/ERK1/2 and $p-m T O R / m T O R$. As the ERK $1 / 2$ pathway is one of the most influential pathways associated with cellular responses to various external stimuli and mTOR has an important role as the mammalian target of RPM, we next examined the involvement of these proteins during the RPM treatment and lncRNA SENCR overexpression in HUVECs. Fig. 8A showed the expression of several proteins involved in the RPM-related signaling pathway in HUVECs, demonstrating that the phosphorylation of ERK1/2 and mTOR proteins decreased upon RPM treatment. However RPM+lncRNA-SENCR OE treatment alleviated the downregulation of $\mathrm{p}$-ERK1/2 and p-mTOR proteins caused by RPM treatment. Specifically, RPM+lncRNA-SENCR OE treatment reversed the decrease of the $\mathrm{p}-\mathrm{ERK} 1 / 2 / \mathrm{ERK} 1 / 2$ ratio caused by $\mathrm{RPM}$ treatment to the normal level $(\mathrm{P}<0.01$, vs. RPM group; Fig. $8 \mathrm{~B})$. It was noted that RPM+lncRNA-SENCR OE treatment also significantly increased the ratio of $\mathrm{p}-\mathrm{mTOR} / \mathrm{mTOR}$ ( $\mathrm{P}<0.05$ vs. RPM group; Fig. 8C). These results suggested that, as shown in Fig. 9, RPM treatment could inhibit the activation of the ERK1/2 and mTOR pathway, and overexpression of IncRNA SENCR could relieve the inhibitory effect of RPM on the ERK1/2 and mTOR pathway.

\section{Discussion}

In this study, we provided evidence for the fact that the lncRNA SENCR alleviates the effects of RPM inhibition on HUVECs. The results indicated that the lncRNA SENCR alleviated the inhibition of cellular proliferation, migration, angiogenesis and cell cycle progression of HUVECs directly or interfering with the inhibition progress of ERK $1 / 2$ and m-TOR phosphorylation in the presence of RPM. It is reasonable to conclude that RPM and lncRNA SENCR interact negatively during the processes of proliferation and migration of HUVECs.

RPM has been used in first-generation intracoronary DESs, and its use markedly reduces restenosis following stenting (1-3). However, RPM not only inhibits smooth muscle cell proliferation but also reduces endothelial cell proliferation, preventing re-endothelialization post-DES implantation $(4,5)$. More recently, second-generation stents that use biocompatible or biodegradable polymers and more effective agents appeared and replaced RPM stents in the western world. However, RPM stents dominate in China and most Chinese patients select RPM stents because of price and medical insurance. Therefore, the side effects of RPM on endothelial cells and corresponding intervention strategies remain worthwhile areas of study.

Recently, IncRNAs, which is more than 200 base pairs between protein-coding genes and has their own promoters, 

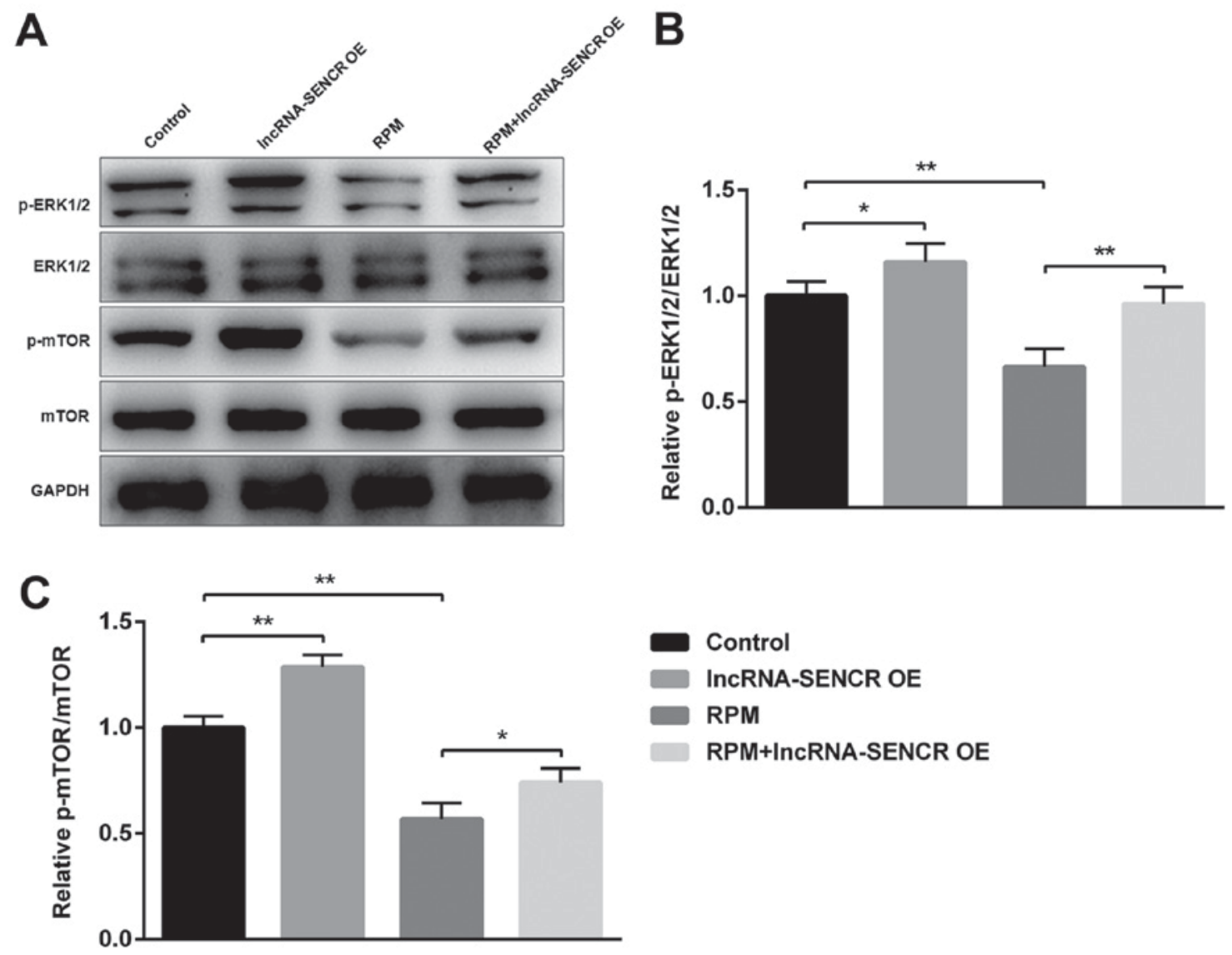

Figure 8. Ratios of p-ERK1/2/ERK1/2 and p-mTOR/mTOR of HUVECs after treatments with lncRNA-SENCR OE, RPM and RPM+lncRNA-SENCR OE. (A) Representative images of protein expression by western blot analysis. (B) $\mathrm{p}$-ERK1/2/ERK1/2 ratio. (C) $\mathrm{p}-\mathrm{mTOR} / \mathrm{mTOR}$ ratio. $(\mathrm{n}=3)$. ${ }^{*} \mathrm{P}<0.05$, ${ }^{* *} \mathrm{P}<0.01$. p-ERK, phosphorylated extracellular signal-regulated kinase; mTOR, mammalian target of rapamycin; HUVEC, human umbilical vein endothelial cell; lnc, long non-coding; SENCR, smooth muscle and endothelial cell-enriched migration/differentiation-associated RNA; OE, overexpression; RPM, rapamycin.

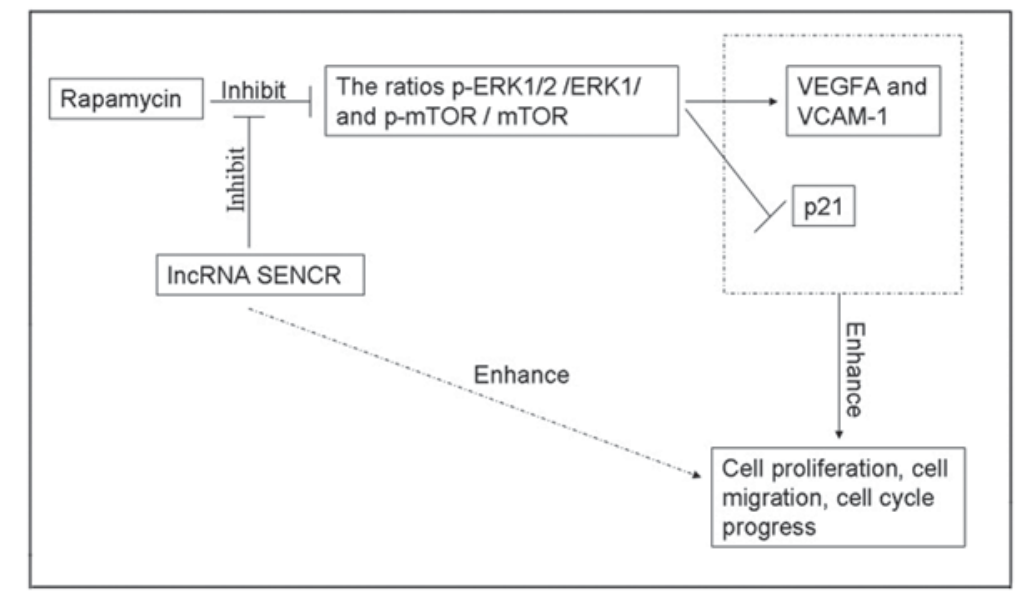

Figure 9. Possible mechanism of the association between RPM treatment and lncRNA SENCR. RPM, rapamycin; VEGF, vascular endothelial growth factor; VCAM-1, vascular cell adhesion protein-1; p-ERK, phosphorylated extracellular signal-regulated kinase; mTOR, mammalian target of rapamycin; SENCR, smooth muscle and endothelial cell-enriched migration/differentiation-associated RNA; lnc, long non-coding.

are emerging as novel molecular switches in cellular differentiation, movement and apoptosis by altering gene expression patterns. A number of studies have demonstrated that lncRNAs can be targeted to change cellular physiology and functions of vascular endothelial cell function and may be a promising therapeutic target for angiogenesis (19-24). Michalik et al found that genetic deletion of MALAT1 gene have demonstrated reduced retinal vascular growth and endothelial growth in vivo (15). One recent study proposed the circulating lncRNAs including SENCR could be used as biomarkers of heart function and remodeling in type 2 diabetes (25). However, few reports have focused on the action of these two IncRNAs in the presence of RPM, which has been investigated in the present study. 
Since lncRNAs MALAT1 and SENCR have demonstrated enhancement of endothelial cell proliferation and migration $(14,16,17,25-27)$, we hypothesized that overexpression of them may alleviate the inhibitory effects of RPM on HUVEC. The work described here studied the expression of IncRNA SENCR and MALAT1 in HUVECs after RPM treatment and found that lncRNA SENCR expression decreased more significantly than that of IncRNA MALAT1 when exposed to RPM. This result implied that the lncRNA SENCR might serve as a sensitive indicator of endothelial cell function judgement in patients treated with RPM-eluting stents. We further demonstrated that transfection of IncRNA SENCR abolished the inhibitory effects of RPM on the proliferation, cell migration, sprouting and cell cycle progression of HUVECs. Besides the regulation of endothelial proliferation, migration, and angiogenesis, SENCR induced endothelial development and function were also evidenced by Boulberdaa and co-wokers (17). To understand the targeted gene modulated by lncRNA SENCR during angiogenesis-related function, some pro-angiogenic genes can be focused on. Boulberdaa's work studied CCL5, CEACAM1 and CX3CL1 as targeted genes. They confirmed that knockdown of SENCR resulted in a decrease of these genes and its overexpression induced an upregulation of CCL5 and CX3CL1. Similarly, we focused on $V E G F A$ and VCAM-1, and $\mathrm{p} 21$ and data indicated that 1 ncRNA SENCR overexpression effectively restored the transcriptional level of VEGFA and VCAM-1, and inhibited p21 post-RPM treatment, which at least partly contributed to the augmentation of HUVEC function.

Besides regulatory proteins and microRNAs, IncRNAs are emerging critical regulatory moleculars for the control of the mTOR signaling circuit. Further, because RPM is a famous mTOR inhibitor, we try to assess related proteins in the ERK $1 / 2$ and mTOR pathways. Consistent with previous reports $(28,29)$, the results revealed that both p-ERK1/2/ERK1/2 and p-mTOR/mTOR exhibited increased levels following lncRNA SENCR upregulation. Based on the above data and analysis, we conclude the likely mechanism of action of lncRNA SENCR via relieving the inhibitory effect of RPM on ERK1/2 and mTOR pathways and promoting HUVEC proliferation and migration.

In conclusion, this work gives novel insight into the regulatory of vascular endothelial functions by lncRNAs after RPM-eluting grafts implantation. In patients carrying RPM-eluting stent grafts, IncRNA SENCR might be used to evaluate the endothelial cell performance. Additionally, the nice enhancement of endothelial cell function made lncRNA SENCR a promising agent for improving the efficacy of RPM-eluting stents after implantation. In light of the diversity of the mode of action of IncRNAs, more RPM-related lncRNAs and their underlying mechanisms need to be explored in future research.

\section{Acknowledgements}

Not applicable.

\section{Funding}

No funding was received.

\section{Availability of data and materials}

All the data used in the current study are available from the corresponding author on reasonable request.

\section{Authors' contributions}

HT conceived and designed the study. Construction of overexpression plasmid and cellular experiments were performed by SY. mRNA and protein related experiments were performed by MS. All the authors participated in the data analysis and manuscript writing.

\section{Ethics approval and consent to participate}

Not applicable.

\section{Consent for publication}

Not applicable.

\section{Competing interests}

The authors declare that there are no competing interests.

\section{References}

1. Werner M: Drug eluting stents and modern stent technologies for in-stent restenosis. J Cardiovasc Surg (Torino) 58: 497-500, 2017.

2. Guo N, Chen F, Zhou J, Fang Y, Li H, Luo Y and Zhang Y: Curcumin attenuates rapamycin-induced cell injury of vascular endothelial cells. J Cardiovasc Pharmacol 66: 338-346, 2015.

3. Matter CM, Rozenberg I, Jaschko A, Greutert H, Kurz DJ, Wnendt S, Kuttler B, Joch H, Grünenfelder J, Zünd G, et al: Effects of tacrolimus or sirolimus on proliferation of vascular smooth muscle and endothelial cells. J Cardiovasc Pharmacol 48: 286-292, 2006.

4. Chong E, Poh KK, Liang S, Lee RC, Low A, Teo SG and Tan HC: Two-year clinical registry follow-up of endothelial progenitor cell capture stent versus sirolimus-eluting bioabsorbable polymer-coated stent versus bare metal stents in patients undergoing primary percutaneous coronary intervention for ST elevation myocardial infarction. J Interv Cardiol 23: 101-108, 2010.

5. Liu HT, Li F, Wang WY, Li XJ, Liu YM, Wang RA, Guo WY and Wang HC: Rapamycin inhibits re-endothelialization after percutaneous coronary intervention by impeding the proliferation and migration of endothelial cells and inducing apoptosis of endothelial progenitor cells. Tex Heart Inst J 37: 194-201, 2010.

6. Booy EP, McRae EK, Koul A, Lin F and McKenna SA: The long non-coding RNA BC200 (BCYRN1) is critical for cancer cell survival and proliferation. Mol Cancer 16: 109, 2017.

7. Hua F,Liu S,Zhu L, MaN,Jiang S and Yang J: Highly expressed long non-coding RNA NNT-AS1 promotes cell proliferation and invasion through $\mathrm{Wnt} / \beta$-catenin signaling pathway in cervical cancer. Biomed Pharmacother 92: 1128-1134, 2017.

8. Li J, Chen Y, Chen Z, He A, Xie H, Zhang Q, Cai Z, Liu Y and Huang W: SPRY4-IT1: A novel oncogenic long non-coding RNA in human cancers. Tumor Biol 39: 1010428317711406, 2017.

9. Li Y, Jiang B, Zhu H, Qu X, Zhao L, Tan Y, Jiang Y, Liao M and $\mathrm{Wu} X$ : Inhibition of long non-coding RNA ROR reverses resistance to Tamoxifen by inducing autophagy in breast cancer. Tumor Biol 39: 1010428317705790, 2017.

10. Zhang CY, Yu MS, Li X, Zhang Z, Han CR and Yan B: Overexpression of long non-coding RNA MEG3 suppresses breast cancer cell proliferation, invasion, and angiogenesis through AKT pathway. Tumor Biol 39: 1010428317701311, 2017.

11. Zhang R, Xia Y, Wang Z, Zheng J, Chen Y, Li X, Wang Y and Ming $\mathrm{H}$ : Serum long non coding RNA MALAT-1 protected by exosomes is up-regulated and promotes cell proliferation and migration in non-small cell lung cancer. Biochem Biophys Res Commun 490: 406-414, 2017. 
12. Zhang Y and Hu H: Long non-coding RNA CCAT1/miR-218/ZFX axis modulates the progression of laryngeal squamous cell cancer. Tumor Biol 39: 1010428317699417, 2017.

13. Xu JH, Chang WH, Fu HW, Shu WQ, Yuan T and Chen P Upregulated long non-coding RNA LOC90784 promotes cell proliferation and invasion and is associated with poor clinical features in HCC. Biochem Biophys Res Commun 490: 920-926, 2017.

14. Thum T and Kumarswamy R: The smooth long noncoding RNA SENCR. Arterioscler Thromb Vasc Biol 34: 1124-1125, 2014

15. Michalik KM, You X, Manavski Y, Doddaballapur A, Zörnig M, Braun T, John D, Ponomareva Y, Chen W, Uchida S, et al: Long noncoding RNA MALAT1 regulates endothelial cell function and vessel growth. Circ Res 114: 1389-1397, 2014

16. Bell RD, Long X, Lin M, Bergmann JH, Nanda V, Cowan SL, Zhou Q, Han Y, Spector DL, Zheng D and Miano JM: Identification and initial functional characterization of a human vascular cell-enriched long noncoding RNA. Arterioscler Thromb Vasc Biol 34: 1249-1259, 2014.

17. Boulberdaa M, Scott E, Ballantyne M, Garcia R, Descamps B, Angelini GD, Brittan M, Hunter A, McBride M, McClure J, et al: A role for the long noncoding RNA SENCR in commitment and function of endothelial cells. Mol Ther 24: 978-990, 2016.

18. Livak KJ and Schmittgen TD: Analysis of relative gene expression data using real-time quantitative PCR and the 2(-Delta Delta C(T)) method. Methods 25: 402-408, 2001.

19. Jen J, Tang YA, Lu YH, Lin CC, Lai WW and Wang YC: Oct4 transcriptionally regulates the expression of long non-coding RNAs NEAT1 and MALAT1 to promote lung cancer progression. Mol Cancer 16: 104, 2017.

20. Li C, Cui Y, Liu LF, Ren WB, Li QQ, Zhou X, Li YL, Li Y, Bai XY and Zu XB: High expression of long noncoding RNA MALAT1 indicates a poor prognosis and promotes clinical progression and metastasis in bladder cancer. Clin Genitourin Canc 15: 570-576, 2017.

21. Pruszko M, Milano E, Forcato M, Donzelli S, Ganci F, Di Agostino S, De Panfilis S, Fazi F, Bates DO, Bicciato S, et al: The mutant p53-ID4 complex controls VEGFA isoforms by recruiting lncRNA MALAT1. EMBO Rep 18: 1331-1351, 2017.
22. Sun JY, Zhao ZW, Li WM, Yang G, Jing PY, Li P, Dang HZ, Chen Z, Zhou YA and Li XF: Knockdown of MALAT1 expression inhibits HUVEC proliferation by upregulation of miR-320a and downregulation of FOXM1 expression. Oncotarget 8: 61499-61509, 2017.

23. Wang C, Mao ZP, Wang L, Wu GH, Zhang FH, Wang DY and Shi JL: Long non-coding RNA MALAT1 promotes cholangiocarcinoma cell proliferation and invasion by activating PI3K/Akt pathway. Neoplasma 64: 725-731, 2017.

24. Wu L, Wang X and Guo Y: Long non-coding RNA MALAT1 is upregulated and involved in cell proliferation, migration and apoptosis in ovarian cancer. Exp Ther Med 13: 3055-3060, 2017.

25. de Gonzalo-Calvo D, Kenneweg F, Bang C, Toro R, van der Meer RW, Rijzewijk LJ, Smit JW, Lamb HJ, Llorente-Cortes V and Thum T: Circulating long-non coding RNAs as biomarkers of left ventricular diastolic function and remodelling in patients with well-controlled type 2 diabetes. Sci Rep 6: 37354, 2016.

26. Zou ZQ, Xu J, Li L and Han YS: Down-regulation of SENCR promotes smooth muscle cells proliferation and migration in $\mathrm{db} / \mathrm{db}$ mice through up-regulation of FoxO1 and TRPC6. Biomed Pharmacother 74: 35-41, 2015.

27. Zhao J, Zhang W, Lin M, Wu W, Jiang P, Tou E, Xue M, Richards A, Jourd'heuil D, Asif A, et al: MYOSLID is a novel serum response factor-dependent long noncoding RNA that amplifies the vascular smooth muscle differentiation program. Arterioscler Thromb Vasc Biol 36: 2088-2099, 2016.

28. Xu C, Zhang H, Liu C, Zhu Y, Wang X, Gao W, Huang S and Chen L: Rapamycin inhibits Erk1/2-mediated neuronal apoptosis caused by cadmium. Oncotarget 6: 21452-21467, 2015

29. Liu P, Yang X, Hei C, Meli Y, Niu J, Sun T and Li PA: Rapamycin reduced ischemic brain damage in diabetic animals is associated with suppressions of mTOR and ERK1/2 signaling. Int J Biol Sci 12: 1032-1040, 2016.

This work is licensed under a Creative Commons Attribution-NonCommercial-NoDerivatives 4.0 International (CC BY-NC-ND 4.0) License. 